\title{
La crisis global, el nuevo papel del Estado y los posibles escenarios pos-Covid-19 \\ Global crisis, new role of the State and possible scenarios pos-Covid-19
}

Jaime Pastor ${ }^{1}$

Resumen: La irrupción de la pandemia de la Covid-19 ha provocado un encadenamiento de crisis entrecruzadas en distintos ámbitos con un alcance global. Sin embargo, se observa cierta recuperación del papel del Estado en la respuesta a los desafíos más inmediatos en el plano sanitario, securitario, económico y social en un contexto de crisis de la globalización neoliberal y de competencia geopolítica entre viejas y nuevas grandes potencias, pero también de agravación del cambio climático y de revalorización de lo público y lo común. En este artículo se subrayan los límites de la escala estatal para afrontar estos retos, pero también las dificultades para superar la actual crisis de

1 Profesor colaborador honorífico de Ciencia Política de la Universidad Nacional de Educación a Distancia, miembro del equipo editorial de Clivatge y de los Consejos de redacción de Geopolítica(s) y Política y Sociedad. Editor de Viento Sur.

B CLIVATGE, número 7

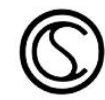


gobernanza global. Finalmente, se apuntan distintos escenarios posibles en un mundo pos-Covid-19: el business as usual, el neosocialdemócrata y el que puede venir de los movimientos sociales que aspiran a un cambio de paradigma civilizatorio. Más allá de estas especulaciones, se concluye que la coexistencia con la inseguridad ante el futuro caracterizará la normalidad en esta nueva era.

Palabras clave: Covid-19, Estados, biopolítica, público, común, proteccionismo, territorio

Abstract: The emergence of the Covid-19 pandemic has unleashed a series of crisscross crises of global reach in different areas. However, there is some recovery of the role of the State in order to respond not only to the most immediate challenges as pertains health, security, economic and social spheres within a context of crisis of neoliberal globalization and geopolitical competition between old and new great powers, but also to the deterioration of climate change and the appreciation of the public and common domains. In this article, the limits of the state scale to meet these challenges are underlined, but also the difficulties to overcome the present crisis of global governance. Different possible scenarios may appear in a post-Covid-19 world: either "business as usual", the neo-social-democratic recipe, or the one that may arise from social movements that aspire to achieve a transformed civilization paradigm. Beyond these speculations, in this new era, coexistence with insecurity in the future will be normalcy.

B CLIVATGE, número 7

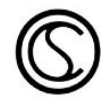


Keywords: Covid-19, states, biopolitics, public, common, protectionism, territory

Resum: La irrupció de la pandèmia de la Covid-19 ha provocat un encadenat de crisis entrecreuades en diferents àmbits d'abast global. Malgrat això, s'observa una certa recuperació del paper de l'Estat en la resposta als desafiaments més immediats en els plans sanitari, securitari, econòmic i social, en un context de crisi de la globalització neoliberal i competència geopolítica entre velles $i$ noves grans potències, però també d'agravació del canvi climàtic $\mathrm{i}$ revalorització d'allò públic i comú. En aquest article, s'hi subratllen els límits de l'escala estatal per fer front a aquests reptes, però també les dificultats per superar la crisi actual de governança global. Per últim, s'hi apunten diferents escenaris possibles en un món post-Covid-19: el business as usual, el neosocialdemòcrata i el que pot venir dels moviments socials que aspiren a un canvi de paradigma civilitzador. Més enllà d'aquestes especulacions, s'hi conclou que la coexistència amb la inseguretat davant el futur caracteritzarà la normalitat en aquesta nova era.

Palabras clave: Covid-19, Estats, biopolítica, públic, comú, proteccionisme, territori

B Clivatge, número 7

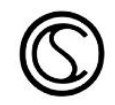


En este trabajo me propongo abordar algunos aspectos de la crisis global generada por el estallido de la pandemia de la Covid-19, convertida en un verdadero punto de inflexión en nuestra historia que obliga a nuevos esfuerzos de reinterpretación de los cambios que está provocando, así como a la búsqueda de nuevas respuestas ante los retos que plantea al conjunto de la humanidad en este siglo XXI. Analizaré los rasgos generales de la crisis global para luego centrarme en el refuerzo del papel del Estado en determinadas esferas competenciales, la remodelación en marcha del sistema de Estados y de la gobernanza global y, finalmente, en los escenarios que se pueden abrir en un mundo pos-Covid-19.

\section{Crisis entrecruzadas}

El impacto de la pandemia de la Covid-19 ha significado, como ya se ha descrito en otros trabajos (Ramonet, 2020; Baschet, 2020), un "hecho social total" que ha provocado una verdadera conmoción en la totalidad de la sociedad global y sus instituciones. Está conduciendo, además, a un encadenamiento de crisis entrecruzadas, con causas diferentes a las vividas en el pasado y, sobre todo, de la más reciente de 2007-2008 por proceder de la expansión de un virus y no de la crisis del sistema financiero, y por haber obligado a la casi paralización de la economía productiva global durante un periodo relativamente corto pero significativo. Diferente también porque introduce un factor de riesgo vital que hasta ahora se creía limitado a los países del Sur o del Este, pero

B CLIVATGE, número 7

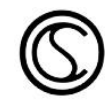


que ahora ha venido para extenderse con toda su gravedad en el Oeste: el de la posible aparición de nuevas pandemias de manera cada vez más frecuente, al menos mientras sigamos en la era del Capitaloceno, ya que "el problema no son los virus: el problema es un sistema socio-económico expansivo (y hasta una dinámica civilizatoria" (Riechmann, 2020). Por eso, a partir de ahora hay que sumar este factor a los cuatro parámetros que superan el techo de sostenibilidad de la vida en el planeta, según un Informe de científicos publicado en 2015, y que afectan al clima, a la biodiversidad, al estado de los ciclos del nitrógeno y a los suelos (Tanuro, 2020).

En esta ocasión se ha manifestado primero mediante una crisis sanitaria, seguida por una crisis económica, cuyo alcance está todavía por ver pero que probablemente conduzca a una Gran Depresión, con sus consecuencias en el plano social cada vez más alarmantes. Con ellas se ha producido una agravación de las desigualdades sociales y de todo tipo que no hacen más que profundizar las fracturas ya existentes en nuestras sociedades y, muy especialmente, dentro de una clase trabajadora feminizada y etnicizada, acentuadas por las nuevas tendencias en marcha, como el crecimiento del teletrabajo y una nueva ronda en la precarización laboral y de las vidas de las mayorías sociales (Carreras, 2020). Un conjunto de procesos que pueden erosionar más todavía las bases materiales necesarias para contrarrestar la deriva autoritaria que

B CLIVATGE, número 7

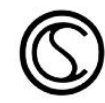


ya estaba en marcha a escala global mucho antes de la irrupción de esta pandemia ${ }^{2}$.

La crisis sanitaria ha mostrado, hasta ahora al menos, su mayor gravedad en los países occidentales, afectados por las políticas neoliberales de recortes y privatizaciones y por su dependencia de un sistema industrial de aprovisionamiento deslocalizado para atender a situaciones de emergencia como la vivida ahora. A todo esto se ha unido el retraso en la respuesta ante esta pandemia, pese a los avisos que habían llegado desde distintos observatorios (Ramonet, 2020), confirmando el lastre del viejo supremacismo occidental que hacía pensar que nunca iban a llegar a estas tierras epidemias tan letales como las sufridas en otras regiones del mundo. Se ha llegado así a un colapso sanitario que ha tenido en las personas mayores, pero también en un alto número de trabajadores de la sanidad y de los servicios sociales en general, los sectores más perjudicados por la falta de una política de prevención que fuera capaz de poner los medios necesarios para asumir el desafío que suponía esta pandemia.

\section{2. ¿Hacia el Estado protector?}

Dentro de este contexto general, en el que ni la OMS ni otras instituciones y organizaciones internacionales han estado a la altura, estamos asistiendo a una mayor relevancia del marco

2 Con mayor razón ahora porque, como recordaba Adam Przeworski antes del estallido de la actual crisis: "While elites see democracy in institutional terms, several surveys indicate that mass publics often conceive of it in terms of 'social and economic equality" (Przeworski, 2019: 102).

B CLIVATGE, número 7

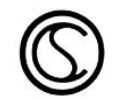


nacionalestatal en la respuesta a la necesidad de garantizar la seguridad sanitaria, pero también la supervivencia de muchas empresas y la asistencia social, junto con las ONG y nuevas redes de apoyo mutuo, a los sectores sociales más vulnerables. En torno a esta cuestión se abre ahora una disputa por el sentido en el que deben orientarse los Estados en un contexto de crisis de la globalización neoliberal, refuerzo de tendencias nacionalproteccionistas e intensa competencia geoestratégica, tecnológica y comercial entre las grandes potencias, especialmente EE UU y China; ambas, a su vez, en proceso de recomposición de sus alianzas respectivas.

La lucha contra la pandemia ha conducido, además, a la mayoría de los gobiernos a proclamar el estado de alarma, acompañándolo de un discurso bélico que ha buscado cerrar filas en las poblaciones respectivas mediante la puesta en pie de planes de confinamiento, con distintas variantes entre ellos, con el propósito común de "salvar vidas". Sin embargo, muy pronto hemos podido comprobar las tensiones entre ese objetivo y el de "salvar la economía" a medida que se ha prolongado esa situación de emergencia. También se ha podido observar una complicada regulación legal que ha permitido restricciones en el ejercicio de determinadas libertades fundamentales, especialmente la libertad de movimiento, pero también de otras como la libertad de expresión y los derechos de reunión y manifestación. Restricciones que, si bien han podido justificarse por la situación de estado de alarma, han conducido en ocasiones a cierto grado de arbitrariedad por parte de las autoridades.

B CLIVATGE, número 7

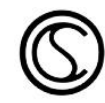


Ha entrado así en la agenda política de los Estados una política de seguridad que, estimulada por las experiencias de China, pero también por las de países con regímenes demoliberales, como Corea del Sur, Taiwan o Singapur, puede suponer un salto adelante enorme en el uso de medios digitales, destinado a implantar un control del conjunto de la población que, justificado ahora por razones sanitarias, podría transformarse en normal en el nuevo periodo abierto para "el día después. No faltan las alertas ante el camino que se podría abrir por parte de muchos Estados para imponer un control necrobiopolítico permanente de la población (Preciado, 2020), apoyado en la asociación cada vez más estrecha entre los Estados y los GAFAM (Google, Amazon, Facebook, Apple y Microsoft) del capitalismo digital. Una hipótesis nada despreciable porque, como se denuncia en el Manifiesto La necesidad de luchar contra un mundo 'virtual' | ctxt.es, "un vistazo a la historia reciente de la tecnología muestra que los dispositivos liberticidas que se introducen en tiempos de crisis casi nunca desaparecen"; con la coartada en este caso de que, como ya se ha indicado antes, la amenaza de nuevas pandemias va a formar parte de nuestro futuro de inseguridad(es) permanente(s).

Es fácil comprobar, por tanto, el refuerzo del poder soberano de los Estados en el plano securitario, con las personas demandantes de refugio como principales víctimas del cierre de fronteras, como ya ocurre desde hace tiempo en EE UU y en la UE, pero también dentro de las mismas, como estamos viendo ahora en Grecia y en los países del Golfo. Un poder soberano que va a permitir su uso para el control de los espacios públicos virtuales y reales en los que se

B CLIVATGE, número 7

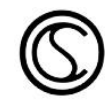


puedan expresar las distintas formas de protesta que no cuenten con el agrado de las autoridades afectadas; o, simplemente, para disuadir de la protesta, ya que como también se recuerda en el Manifiesto antes citado: "El hecho de saberse constantemente vigilado es fuente comprobada de conformismo y sumisión a la autoridad, incluso cuando no se vive en una dictadura".

Es también en el plano económico y social donde la recuperación de competencias por parte de muchos Estados es reclamada desde diferentes corrientes políticas e ideológicas. Dada la magnitud de la catástrofe que se anuncia en cuanto al descenso del PIB, a la quiebra de un alto número de pequeñas y grandes empresas $\mathrm{y}$, sobre todo, al aumento del paro, la precarización y el empobrecimiento de la mayoría de las poblaciones, la apelación al Estado como "salvador" es también recurrente. El debate está en torno a qué sentido va a tener esa intervención estatal en un contexto en el que parece evidente la pérdida de credibilidad de algunas de las ideasfuerza y de las políticas neoliberales en ámbitos como el de la sanidad y los servicios públicos en general.

No conviene olvidar que en el pasado el papel de los Estados ha sido también muy activo, sobre todo en su versión ordoliberal, a través de su ensamblaje creciente con el sistema financiero y a los mercados. Un papel activo que viene ya de la larga onda neoliberal iniciada a finales de los años 70 del pasado siglo y que, tras el inicio de la Gran Recesión en 2007-2008, adquirió un nuevo impulso mediante políticas de rescate al sistema financiero y medidas austeritarias contra las clases subalternas. Un proceso que en el ámbito de la Unión Europea y de la eurozona en particular condujo

B CLIVATGE, número 7

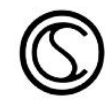


a la acentuación de las desigualdades entre el Norte occidental, por un lado, y las periferias del Sur y del Este, con Grecia como principal afectada, por otro.

La novedad en el panorama con el que nos estamos encontrando ahora es que, en medio del agotamiento del régimen de acumulación capitalista global iniciado a mediados de los años 70 del pasado siglo y del desarrollo nuevas tendencias proteccionistas en el plano comercial, los Estados van a tener que hacer compatibles, por un lado, un nuevo rescate a la economía productiva y, por otro, la respuesta a una demanda creciente de una respuesta a la catástrofe social muy superior a la iniciada en 2007-2008. Se trata en realidad de una vieja tensión dentro de los Estados entre la función prioritaria destinada a garantizar las condiciones de producción y reproducción capitalista y, a la vez, la que exige mantener un grado de legitimación suficiente entre las clases subalternas que asegure la estabilidad política necesaria. El problema está ahora en que no va a ser fácil gestionarla en la nueva etapa histórica que se abre, con mayor razón cuando ya ha entrado en la agenda política la urgencia de una transición energética y ecológica.

Se anuncia, por tanto, un conjunto de políticas estatales que exige, sobre todo, un aumento extraordinario del gasto público para cubrirlas y que, de no ir apoyadas en una reforma fiscal radical, van a provocar un endeudamiento público y privado de magnitudes mayores que las conocidas hasta ahora. Una amenaza que podría verse atenuada si, como ya se reclama desde muchos países del Sur, se logra una cancelación de la deuda o, en el caso europeo, se llega

B CLIVATGE, número 7

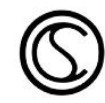


a un acuerdo en torno a los fondos de solidaridad sin condiciones, ya que, de no ser así, puede convertirse en una espada de Damocles para las futuras generaciones a escala global.

Es probablemente en el marco de la Unión Europea donde las limitaciones del marco nacionalestatal para responder a esta crisis global son más perceptibles si tenemos en cuenta el grado de interdependencia entre las economías de los Estados miembros, especialmente entre los países que forman parte de la eurozona, así como la necesidad de contrarrestar -sobre todo, por parte de Alemania, su principal potencia-la tendencia al declive de su peso dentro del contexto geopolítico global. La suspensión del Pacto de Estabilidad presupuestaria, las propuestas de un fondo de ayudas por parte de la Comisión Europea y el papel más activo del Banco Central Europeo para garantizar la liquidez necesaria que ayude al relanzamiento económico del conjunto de la UE apuntan a un intento de superar las tensiones surgidas en su seno, derivadas de la agravación de las desigualdades entre los países miembros -y dentro de los mismos-provocada por la pandemia.

\section{La revalorización de lo público}

Lo que sí va a ser difícil es que se repita el escenario que se impuso en 2007-2008, aunque sin duda es lo que van a intentar las fracciones más transnacionalizadas de las clases dominantes. La revalorización de lo público y de las actividades esenciales, entre ellas todas las relacionadas con los cuidados, frente a los recortes y privatizaciones que se generaron entonces, es tan patente que una

B CLIVATGE, número 7

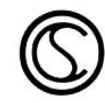


salida similar a la anterior provocaría una creciente inestabilidad política y social de difícil gestión por parte de los gobiernos.

Ese sentido común de lo público se ha visto además reforzado porque se ha extendido su concepción, no como un derecho del Estado, sino como un deber, una obligación, ya que, como sostienen Pierre Dardot y Christian Laval (2020), "los servicios públicos no son los servicios del Estado en el sentido de que el Estado pueda disponer de ellos a su antojo, no son tampoco una proyección del Estado, son públicos en el sentido en que están 'al servicio del público". Lo mismo podríamos decir de cantidad de actividades que se han demostrado esenciales y que, por tanto, deberían escapar a la lógica del mercado interior y exterior (como es el caso de la industria farmacéutica), así como a las condiciones de sobreexplotación en las que se encuentran quienes trabajan en ellas. Una percepción que se está extendiendo al conjunto de bienes públicos y comunes dedicados a satisfacer las necesidades básicas de la población. No cabe sorprenderse, por tanto, de que términos como nacionalizaciones o planificación económica y ecológica estén volviendo a la agenda política, incluso en boca de líderes políticos como el presidente francés Macron ${ }^{3}$, quien ha llegado a reivindicar el ejemplo del Consejo Nacional de la Resistencia surgido en su país después del final de la Segunda Guerra Mundial.

3 "Il nous faudra bâtir une stratégie où nous retrouvons le temps long, la possibilité de planifier, la sobrieté carbone, la prévention, la résilience qui seule peuvent permettre de faire face aux crises à venir", "Nous tiendrons", Le Monde, $13 / 04 / 2020$. No obstante, como ocurrió en la anterior crisis con Sarkozy, sigue sin reflejarse en propuestas concretas.

B CLIVATGE, número 7

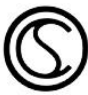


En todo caso, la hipótesis de nuevas formas de capitalismo occidental en las que el Estado asuma un papel más activo y centralista ${ }^{4}$ en la búsqueda de un modelo económico no tan dependiente del exterior en algunas actividades esenciales, una política asistencial sustancialmente superior a la anterior a la crisis $\mathrm{y}$, a su vez, un refuerzo del control social bajo formas más autoritarias, no puede ser descartada. Sería un nuevo tipo de despotismo estatal protector (arropado por el saber experto sistémico) que aspiraría a una legitimación de ejercicio entre quienes comparten la identidad nacionalestatal dominante, en nombre del miedo a la inseguridad permanente. Una tendencia que les acercaría a las denominadas democracias iliberales, con Rusia o Turquía como referentes, que ya está en marcha en algunos países de Europa del Este -como Polonia y Hungría-y que podría darse en EE UU en el caso de que Trump viera renovado su mandato en noviembre de este año.

\section{Crisis de gobernanza global}

Esas tendencias podrían ir, por tanto, acompañadas de un reajuste parcial en las cadenas transnacionles de creación de valor mediante cierta relocalización de determinadas actividades productivas, sin

\footnotetext{
${ }^{4}$ Un rasgo que ha caracterizado la aplicación del estado de alarma en el caso español, ya que desde el principio se estableció un "mando único", sin previa deliberación con las CC AA y sin implicación alguna de las mismas en la toma de decisiones, apenas compensada luego por la celebración semanal de Conferencias de Presidentes de las CC AA que son prácticamente consultivas, pese a definir ese proceso en una fase posterior con el neologismo de "cogobernanza".
}

B CLIVATGE, número 7

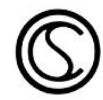


cuestionar no obstante la primacía del sistema financiero, cuyo grado de autonomía, de movilidad global y de presión sobre la mayoría de los Estados sigue siendo notable.

Mientras tanto, la inestabilidad geopolítica sigue su curso en un mundo en lucha por el control de los recursos energéticos cada vez más escasos y con nuevos alineamientos regionales, incluso dentro de una UE en "crisis existencial", como la definió uno de sus líderes políticos. Todo esto en medio de un proceso de cambio de relaciones de fuerzas entre las viejas y las nuevas grandes potencias, pero sin que "el repliegue internacional de un imperio [el estadounidense] que abandona su disfraz de auxiliador del mundo", (Katz, 2020) esté llevándole a su crisis terminal (lo cual exigiría un detonante similar a lo que significó la catástrofe nuclear de Chernóbil para la URSS o la crisis del Canal de Suez para Gran Bretaña) como hegemón. No olvidemos que su pérdida de posiciones en el plano comercial y tecnológico e incluso cultural (agravado por el repliegue etnonacionalista y el "nuevo 68" que se está viviendo en ese país bajo Trump) no impide a esta gran potencia seguir contando, además de con su superior poder militar (pese a su incapacidad demostrada para aplicar la "destrucción creativa" predicada en zonas como Oriente Medio), con los derechos de señoreaje sobre el dólar y con la particularidad de ser sede matriz de gran parte del capital transnacional ${ }^{5}$ que se ha extendido por el mundo.

5 Tenemos un reciente ejemplo de esto en la presión que está ejerciendo la Administración de EE UU sobre países de la UE para que renuncien a aplicar el impuesto conocido como tasa Google.

B CLIVATGE, número 7

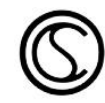


En ese contexto, el único competidor a medio plazo de la gran potencia estadounidense es sin duda China debido a su ascenso económico, tecnológico y comercial, a sus planes en marcha (como la nueva ruta de la seda), a su aspiración hegemónica en la región de AsiaPacífico y a su soft power a escala internacional. Con todo, China también se va a encontrar con obstáculos para proseguir su ascenso, debido a su mayor necesidad de acceso directo del mercado mundial, así como a su dependencia externa en materia energética y agrícola (Golub, 2020). Se entiende, por tanto, que para Trump su objetivo sea, como observa Michael Roberts, "bloquear el comercio con aranceles, bloquear el acceso de China a nuevas tecnologías y a sus exportaciones, aplicar sanciones a las empresas chinas y enfrentar a los deudores con China". Así que, como también aventura Roberts: "La 'guerra fría' comercial, tecnológica y política se 'calentará' más esta década, como el propio planeta" (Roberts, 2020).

Será en relación con esa competencia geoestratégica entre la gran potencia en declive y la que aparece hoy en ascenso como parece que se van a tener que mover otras relativamente grandes y medianas potencias, cuyos alineamientos, más allá de la reactivación del G20, se verán condicionados por su estatus geopolítico dentro del sistema jerárquico de Estados y por su mayor o menor dependencia económica, energética y tecnológica, pero también por factores de orden cultural e ideológico. Todo esto en medio de una transición geopolítica en la que la pérdida de centralidad que Occidente había mantenido hasta ahora parece ya irreversible.

B CLIVATGE, número 7

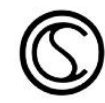


En ese marco de mayor inestabilidad geopolítica global, la combinación de conflictos relacionados con las crisis entrecruzadas ya mencionadas y, simultáneamente, de tensiones internas en torno a otras líneas de fractura preexistentes nacionales, étnicas-puede dar lugar a un aumento del número de Estados frágiles y/o fallidos en distintas regiones del planeta, e incluso a una fase de militarización y guerras, sin que haya instituciones internacionales con la suficiente autoridad para ejercer de mediadoras.

Sin embargo, desafíos globales como la necesidad de prevenir nuevas pandemias, la creación de condiciones favorables para superar el estancamiento secular y sentar las bases de un nuevo régimen de acumulación y, sobre todo, la respuesta al cambio climático, continuarán mostrando las limitaciones de las respuestas a escala nacionalestatal y presionarán por la búsqueda de nuevas formas de gobernanza global. El problema está en que, como escribían Michael Hardt y Antonio Negri antes de la pandemia de la Covid 19, "la contrarrevolución neoliberal ha creado una esfera de gobernanza sin relación estructural estable con la esfera de la producción y la reproducción sociales" (Hardt y Negri, 2020). De ahí las mayores limitaciones mostradas por instituciones supranacionales como la ONU o la OMS (cuestionadas además por la actual Administración estadounidense) y, a la vez, el protagonismo que siguen teniendo otras, como el FMI y el BM, más dependientes de la influencia de los grandes lobbies financieros transnacionales.

B Clivatge, número 7

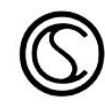




\section{5. ¿Qué escenarios?}

No faltan ya especulaciones sobre escenarios de futuro posibles que podrían ir haciéndose realidad más allá de la escala nacionalestatal. Una de ellas es la que propone Alain Bihr (2020) en torno a tres posibles: uno sería el de business as usual (BAU); otro el de una neosocialdemocracia adaptada a los nuevos tiempos del green-washing; y otro, en fin, el que podría abrir algunas brechas que permitieran ofrecer un horizonte alternativo distinto del actual modelo civilizatorio. Unos escenarios que tienen puntos comunes con los que comenta Luis González Reyes en otro artículo (2020) y que aparecen más desarrollados en el Informe de Ecologistas en Acción "Escenarios de trabajo en la transición ecosocial 2020-2030"6, recientemente publicado, y en donde el tercero sería el basado en un proyecto de decrecimiento, necesariamente rupturista en el plano civilizatorio.

En realidad, ya hemos visto un primer ensayo del primero en la tensión que se ha creado entre "salvar vidas" o "salvar la economía" a la hora de determinar cuáles eran los servicios esenciales a preservar en pleno confinamiento. Si Trump y Bolsonaro han sido los principales protagonistas en su defensa, no han faltado otros entre las derechas y los think tank de las grandes patronales de todos los países, empeñados incluso en establecer unos criterios monetarios sobre cuál sería el "valor de vida" (Husson, 2020), cuando no en un criterio de discriminación por edad o capacitismo para el tratamiento en los centros sanitarios. Sería un escenario

${ }^{6}$ Se puede consultar en www.ecologistasenaccion.org/132893 
que, una vez pasada la fase asistencialista de emergencia, implicaría un retorno, en resumen, a repetir la experiencia posterior a la Gran Recesión de 2008 con la coartada del pago de la deuda para una nueva vuelta de tuerca en reformas estructurales. En resumen, sería un modelo que podría tener dos variantes: "neoliberalismo restaurado" y "neo-iliberalismo", como sugieren Escalona y Godin, 2020.

Otro escenario sería el que combinara, por un lado, un reforzamiento del sector público en la sanidad y servicios sociales en general-con alguna forma de renta mínima para las capas más empobrecidas, $y$, por otro, un nuevo partenariado del Estado con las grandes empresas que asumiera algunos de los retos del Green New Deal, compatibles con el fetichismo del crecimiento económico, como ya se propone desde distintos sectores políticos y sociales. En resumen, la puesta en pie de nuevos pactos interclasistas que, aun siendo asimétricos, evitaran la crisis de legitimidad que podría sufrir el primer escenario, sobre todo en su versión dura.

Finalmente, también se abre la posibilidad de una nueva ola de revueltas populares que tomen el relevo de las que estaban en marcha antes del estallido de esta crisis global y apunten hacia un tercer escenario. La ola de protestas que se ha extendido en EE UU $\mathrm{y}$ en otros lugares del mundo frente al racismo estructural recientemente puede ser un anticipo de lo que puede ocurrir en esta nueva era. Movimientos como el feminista en Chile y otros países ya han sido motores de algunas de esas revueltas en el

B CLIVATGE, número 7

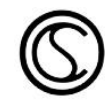


pasado reciente, y el movimiento ecologista y las nuevas formas de sindicalismo social y barrial pueden llegar a serlo en otros.

Obviamente, el salto de la protesta a la propuesta, a la articulación de nuevos bloques sociales a favor de la socialización de lo público y lo común y del reparto de todos los trabajos para apostar por otro mundo posible, no es automático, máxime en unas condiciones de mayor debilitamiento estructural de las clases subalternas y de ascenso de populismos de extrema derecha. Hará falta un nuevo ciclo de movilizaciones sostenidas que vaya más allá del ámbito estatal y pueda ir forjando alianzas solidarias entre pueblos, al menos a escala regional, en torno a un nuevo cambio de paradigma civilizatorio.

A las razones de las revueltas anteriores y a las derivadas de las que agudiza esta crisis global se suman ahora, además, las vividas durante el "Gran Confinamiento". Esta experiencia ha permitido innovar formas de protesta desde las redes sociales, pero ha dado un mayor valor a la necesidad del encuentro físico, a la interacción de los cuerpos y los afectos, a la discusión, a la deliberación y la acción colectiva anclada en el territorio, en el vecindario, en la fuerza de la gente.

\section{A modo de conclusiones}

Se abre, por tanto, una ventana de oportunidad para las peores distopías, pero también para otro horizonte de utopías creíbles y factibles, ya que, con palabras de Bruno Latour (2020): "En medio del dolor más extremo, estamos viendo que el orden mundial, que se nos decía que era imposible de cambiar, tiene una plasticidad

B CLIVATGE, número 7

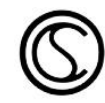


asombrosa, y que, como colectivo, los seres humanos no están indefensos".

En ese camino, pese a sus limitaciones, la escala local puede convertirse en un laboratorio a seguir de cerca para conocer la credibilidad y la viabilidad de los distintos escenarios posibles. En realidad, ya hemos visto prácticas prefigurativas de todos ellos en muchas ciudades, barrios y pueblos a lo largo de estos meses de confinamiento: el más autoritario y beligerante frente a cualquier cambio en la política económica y social; el neokeynesiano que apuesta por nuevos pactos interclasistas de reconstrucción social y económica, y el que, queriendo ir más allá, apunta hacia una planificación ecológica y democrática (Durand y Keucheyan, 2020), basada en una nueva economía moral (que ha revalorizado muchos trabajos invisibilizados y ha ensayado ya la reconversión de otros no esenciales), en un decrecimiento selectivo, en una nueva relación entre lo urbano y lo rural, en la solidaridad y el apoyo mutuo.

Más allá de las especulaciones sobre los escenarios posibles, ya que habrá otros híbridos también en disputa, lo que sí es seguro es que entramos en una era en la que el encadenamiento de crisis entrecruzadas conducirá a nuevas polarizaciones sociales y políticas y a los inevitables conflictos de intereses, valores y razones. De todas esas crisis, conviene repetirlo, es la catástrofe ecológica global la que sobredetermina las demás y, por tanto, extraer las lecciones de la actual crisis de la pandemia se hace necesario, ya que, como nos anuncian Descamps y Lebel (2020), esta última sólo ha sido un "aperitivo".

B CLIVATGE, número 7

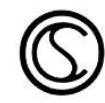




\section{Referencias}

Baschet, Jérôme (2020) “Qu'estce qu'il nous arrive?", Lundimatin [Puesto en línea el 13 de abril de 2020] https://lundi.am/Questce-quilnous arrive-par-Jerome-Bas chet

Bihr, Alain (2020) "Tres escenarios para explorar el campo de lo posible", Viento Sur [Puesto en línea el 23 de abril de 2020] https://www.vientosur.info/spip.php?article15903

Carreras, Judith (2020) "El futuro del trabajo, después del coronavirus", Viento Sur, 170, junio, pp. 60-73.

Dardot, Pierre y Laval, Christian (2020) "La dura prueba política de la pandemia", infolibre [Puesto en línea el 30 de marzo de 2008]

https://www.infolibre.es/noticias/lo mejor mediapart/20 20/03/30/la dura prueba politica pandemia_105414_104 4.html

Descamps, Ph. Y Lebel, Thierry (2020) "Un aperitivo del shock climático", Le Monde Diplomatique, mayo, pp. 1 y 22-23.

Durand, Cédric y Keucheyan, Razmig (2020), Le Monde Diplomatique, mayo, pp. 14-15.

Escalona, F. y Godin, R. (2020) "Les quatre scénarios pour l'hégémonie politique du 'monde d'après"', mediapart.fr, 23/05/2020.

Golub, Philip S. (2020) "Tres hipótesis geopolíticas", Le Monde Diplomatique, junio, pp. 6-7.

González Reyes, Luis (2020) "La época de los triajes", El Salto [Puesto en línea el 18 de abril de 2020] 
https://www.elsaltodiario.com/coronavirus/colapso-crisisclimatica-capitalismo-green-new-deatdecrecimiento-epocat $\underline{\text { riajes }}$

Hardt, M. y Negri, A. (2020) “Imperio, veinte años después”, New Left Review, 120, enerofebrero, pp. 71-98.

Husson, M. (2020) "Sobre la vacuidad de la ciencia económica oficial: el arbitraje entre la actividad económica y los riesgos para la salud", Viento Sur [Puesto en línea el 29 de abril de 2020] https://www.vientosur.info/spip.php?article15929

Katz, Claudio (2020) "La pandemia que estremece al capitalismo. I", Viento Sur [Puesto en línea el 21 de abril de 2020] https://www.vientosur.info/spip.php?article15892

Latour, Bruno (2020) "La plasticidad en el orden mundial”, El País [Puesto en línea el 3 de mayo de 2020] https://elpais.com/especiales/2020/coronavirus-covid-19/ predicciones/latplasticidad-delorden-mundial/

Preciado, Paul B. (2020) "Aprendiendo del virus", El País [Puesto en línea el 28 de marzo de 2020] https://elpais.com/elpais/2020/03/27/opinion/15853169 52 026489.html

Przeworski, Adam (2019) Crises of democracy. Cambridge: Cambridge University Press.

Ramonet, Ignacio (2020) "La pandemia y el sistema-mundo" La jornada [Puesto en línea el 25 de abril de 2020] https://www.jornada.com.mx/ultimas/mundo/2020/04/2 5/ante-lo-desconocido-la-pandemiay-elsistema-mundo-787 8.html 
Riechmann, Jorge (2020) "La crisis del coronavirus desde el ecosocialismo gaiano", Viento Sur, 169, 11-18.

Roberts, Michael (2020) "China: la encrucijada tras la pandemia", sinpermiso, 27 de mayo.

Tanuro, Daniel (2020) "Pandemia, capitalismo y crisis climática", Viento Sur [Puesto en línea el 14 de abril de 2020] https://www.vientosur.info/spip.php?article15861

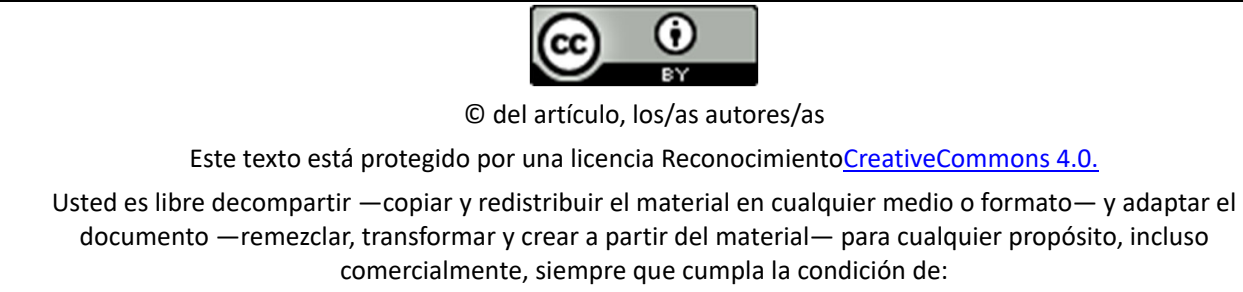
comercialmente, siempre que cumpla la condición de:

Atribución: Usted debe reconocer el crédito de una obra de manera adecuada, proporcionar un enlace a la licencia, e indicar si se han realizado cambios. Puede hacerlo en cualquier forma razonable, pero no de forma tal que sugiera que tiene el apoyo del licenciante o lo recibe por el uso que hace. 